\title{
Reframing Information Literacy as a Metaliteracy
}

\section{Thomas P. Mackey and Trudi E. Jacobson}

\begin{abstract}
Social media environments and online communities are innovative collaborative technologies that challenge traditional definitions of information literacy. Metaliteracy is an overarching and self-referential framework that integrates emerging technologies and unifies multiple literacy types. This redefinition of information literacy expands the scope of generally understood information competencies and places a particular emphasis on producing and sharing information in participatory digital environments.
\end{abstract}

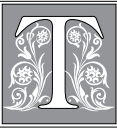

he emergence of social media and collaborative online communities requires a reframing of information literacy as a metaliteracy that supports multiple literacy types. Social media environments are transient, collaborative, and free-flowing, requiring a comprehensive understanding of information to critically evaluate, share, and produce content in multiple forms. Within this context, information is not a static object that is simply accessed and retrieved. It is a dynamic entity that is produced and shared collaboratively with such innovative Web 2.0 technologies as Facebook, Twitter, Delicious, Second Life, and YouTube. Several competing concepts of literacy have emerged including digital literacy, media literacy, visual literacy, and information technology fluency, but there is a need for a comprehensive framework based on essential information proficiencies and knowledge. New media literacy and transliteracy have also responded to the rapid and ongoing changes in technology. As part of a metaliteracy reframing, we argue that producing and sharing information are critical activities in participatory Web 2.0 environments. Information literacy is central to this redefinition because information takes many forms online and is produced and communicated through multiple modalities. Information literacy is more significant now than it ever was, but it must be connected to related literacy types that address ongoing shifts in technology.

Through this overarching approach to information literacy, we examine the term within a new media environment. Metaliteracy promotes critical thinking and collaboration in a digital age, providing a comprehensive framework to effectively participate in social media and online communities. It is a unified construct that supports the acquisition, production, and sharing of knowledge in collaborative online communities. Metaliteracy challenges traditional skills-based approaches to information literacy by recognizing related

Thomas P. Mackey is Interim Dean in the Center for Distance Learning at SUNY Empire State College; e-mail: Tom.Mackey@esc.edu. Trudi E. Jacobson is Head of User Education Programs in the University Libraries of University at Albany, SUNY; e-mail: tjacobson@uamail.albany.edu. (C) Thomas P. Mackey and Trudi E. Jacobson 
literacy types and incorporating emerging technologies. Standard definitions of information literacy are insufficient for the revolutionary social technologies currently prevalent online.

\section{Literacy Frameworks}

We begin with an exploration of traditional information literacy frameworks defined in the most common professional standards. The standards reflect how information literacy is generally understood within the field of library and information science and they continue to inform the learning outcomes mandated by accrediting agencies and developed by course instructors. This examination leads to a review of multiple literacy types in relation to metaliteracy. Over time these competing literacy frameworks have developed in response to emerging technologies, but the connections to information literacy have not always been fully developed or recognized. We are interested in locating similarities among different literacy definitions to support a cohesive metaliteracy framework, with a particular emphasis on the overarching competencies that define literacy in new media environments.

\section{Information Literacy}

Information literacy was the term used most frequently in the United States from the late 1980s through most of the 1990s and is still used regularly. ${ }^{1}$ Professional and educational organizations, such as the American Library Association (ALA), the Association of College and Research Libraries (ACRL), the Society of College, National and University Libraries (SCONUL), and the Middle States Commission on Higher Education (MSCHE), have developed definitions of information literacy and outlined characteristics of information-literate individuals. These definitions share numerous, but not all, of the elements. However, they were all developed prior to the astonishing rise of social media and collaborative online communities and do not fully address the information knowledge required to participate in these new environments.

In 1989, ALA issued the Presidential Committee on Information Literacy: Final Report, which states that students must play an active role in knowing, identifying, finding, evaluating, organizing and using information. ${ }^{2}$ While these elements are generic and applicable to a variety of situations, they do not address the now pervasive online environments in which many forms of information are fluid and information seekers might become information contributors at almost any time and in a public setting. While using information in this standard definition suggests a range of author practices, it exists independently from the act of creating and sharing information through collaborative ventures. The definition adopted by ACRL eleven years later expands upon the ALA definition by emphasizing the depth of the information needed, the ability to find the information effectively and efficiently, the incorporation of new information with existing knowledge, and an understanding of the information environment.

The Society of College, National and University Libraries in the United Kingdom developed the SCONUL Seven Pillars Model for Information Literacy in 1999. The Briefing Paper: Information Skills in Higher Education ${ }^{3}$ outlines seven headline skills or pillars that are similar to those identified by ACRL the following year. SCONUL included "the ability to construct strategies for locating information" ${ }^{4}$ and "the ability to synthesize and build upon existing information, contributing to the creation of new knowledge." 5 These two skills do not appear in ACRL's definition, but they are identified in their standards, performance indicators, and outcomes. ${ }^{6}$ The SCONUL model also specifically addresses increasing levels of competence in each of the seven skills, and it is only when individuals are more expert in their abilities that they reach the level of being able to synthesize and create information. ${ }^{7}$ MSCHE's information 
literacy component goals also address increased abilities from first-year undergraduate through graduate student. ${ }^{8}$

In discussing information skills, SCONUL differentiates between study skills, such "as being able to use an institutional library and its resources to further one's study," ${ }^{\prime \prime}$ and a more advanced skill set that allows people to be prepared for activities and jobs following higher education. This second set includes understanding how information is produced and being able to evaluate it. Specifically referred to is the fact that "it may be textual and published information but will also include other forms of information communication, formal and informal, designed and fortuitous, interpersonal and via information technologies in a much more encompassing way." 10 SCONUL has recently expanded upon the seven headline skills, including examples that acknowledge the changing information environment. ${ }^{11}$ RSS feeds are listed as a way to update information searches, while emphasizing the importance of understanding the source of information and the need to evaluate it carefully.

Social media and online collaborative communities are not specifically addressed in the standard definitions, but many of the highlighted skills are pertinent to today's information environment. The new media context, however, requires a refinement of existing competencies, as well as the recognition of producing and sharing information in collaborative online environments. SCONUL's expanded description of pillar six specifically mentions the need to share information in academic situations, in the personal realm, and in the workplace, using a variety of mediums. ${ }^{12}$ ACRL's standard four, performance indicator three is concerned with communicating information products, using appropriate technologies and designs, to meet the needs of the audience. ${ }^{13}$

The standard definitions respond to trends in the field of library and information science and provide guidance for accrediting agencies and for the development of learning outcomes within courses and programs. At the same time, however, these institutional frameworks are not on the cutting edge of emerging trends; they lag behind the innovations of Web 2.0 and social media. Metaliteracy expands the scope of information literacy as more than a set of discrete skills, challenging us to rethink information literacy as active knowledge production and distribution in collaborative online communities.

Several literacy frameworks have emerged that relate to information and technology in a digital age. Many of these related literacy types share the same skills with information literacy, although in some instances the connections are not a part of the literacy definition. This review of related literacy types illustrates many of the inherent connections to information literacy, supporting a metaliteracy model based on a comprehensive construct for multiple literacy perspectives.

\section{Media Literacy}

In 1992, the Aspen Institute defined media literacy as "the ability of a citizen to access, analyze, and produce information for specific outcomes." ${ }^{14}$ In 2008, the Center for Media Literacy expanded its definition considerably in Literacy for the 21st Century: An Overview and Orientation Guide to Media Literacy Education. ${ }^{15}$ In this update, media literacy "provides a framework to access, analyze, evaluate, create and participate using messages in a variety of forms." ${ }^{16}$ In the revised definition we see similarities to the information literacy characteristics, particularly focused on accessing, analyzing, and evaluating information, but a stronger emphasis is placed on creating and participating, which together "builds an understanding of the role of media in society, as well as essential skills of inquiry and self-expression necessary for citizens of a democracy." ${ }^{17}$ In the expanded description, media literacy is framed within a larger social context that requires individuals to know how to find 
and evaluate information or "messages" and to contribute, using the same tools, in a democratic way. ${ }^{18}$ This emphasis on participation is similar to the standard definition of information literacy that prepares individuals to "use information in such a way that others can learn from them," ${ }^{19}$ but this aspect of information literacy has not been fully developed for interactive digital environments. It is generally understood that the information environment includes technology and that lifelong learning skills prepare individuals to adapt to these changes.

\section{Digital Literacy}

Paul Gilster defines digital literacy as "the ability to access networked computer resources and use them," ${ }^{20}$ which encompasses both the "access" and "use" characteristics of information literacy. Gilster associates digital literacy with critical thinking and argues that one of its core competencies "is the ability to make informed judgments about what you find on-line." ${ }^{21}$ Similarly, Barbara R. Jones-Kavalier and Suzanne L. Flannigan relate digital literacy and critical thinking in Connecting the Digital Dots: Literacy of the 21st Century, stating that this form of literacy is "the ability to read and interpret media (text, sound, images), to reproduce data and images through digital manipulation, and to evaluate and apply new knowledge gained from digital environments." 22 This comprehensive definition of the term includes the critical thinking and evaluative characteristics commonly addressed in information literacy. The authors make direct references to digital technology by stating that "digital literacy represents a person's ability to perform tasks effectively in a digital environment, with 'digital' meaning information represented in numeric form and primarily for use by a computer." ${ }^{23}$ Jones-Kavalier and Flannigan situate the literacy activity within specific digital environments, whereas information literacy tends to focus on broader information environments that necessarily include a range of technologies. The term Information Communication and Technology (ICT) has also been associated with Digital Literacy. The International ICT Literacy Panel defined ICT literacy as "using digital technology, communications tools, and/or networks to access, manage, integrate, evaluate, and create information in order to function in a knowledge society." ${ }^{24}$ This report does not mention information literacy explicitly, even though it shares the same goals for accessing and evaluating information. ${ }^{25}$ In addition, ICT Literacy includes the technical considerations of digital literacy, to be proficient in using technology tools, to manage, integrate, and create information. ${ }^{26}$

\section{Visual Literacy}

While the concept for visual literacy has been around since John Debes introduced it in 1969, recent definitions focus on the relationship of this framework to digital technology. ${ }^{27}$ For instance, in their discussion of digital literacy, Jones-Kavalier and Flannigan make connections to visual literacy, which they define as "focused on sorting and interpreting - sometimes simultaneously - visual actions and symbols." 28 This literacy relates to the "evaluation" and "use" characteristics of information literacy, but this competency is focused more specifically on visual and design issues than standard definitions of information literacy. According to JonesKavalier and Flannigan, "a visually literate person can communicate information in a variety of forms and appreciate the masterworks of visual communication." 29 In addition, they assert that an individual with these visual competencies have "a sense of design - the imaginative ability to create, amend, and reproduce images, digital or not in a mutable way." 30 This part of the definition addresses the participatory nature of digital environments, which may include interactive Web applications or digital editing software, but it also suggests forms that may not be digital. Peter Felton defines visual literacy as a lifelong learning competency 
that "involves the ability to understand, produce, and use culturally significant images, objects, and visible actions. ${ }^{\prime 31} \mathrm{Fel}-$ ton compares the ability to make meaning through images with the ability to communicate through writing and addresses the influence of changing technologies on this process. He argues that "technological change has made it increasingly possible for ordinary people, not just professionals, to become visual designers," ${ }^{\prime 2}$ which suggests that, through this increased access to these digital resources, individuals must be better equipped to make meaning with these tools. In this case, the ability to access, evaluate, and use information relates directly to the visual and is developed within a social context that is mediated by technology.

\section{Cyberliteracy}

Laura J. Gurak introduces the term cyberliteracy to address the communication and participatory aspects of the Internet. ${ }^{33}$ She argues that "cyberliteracy means voicing an opinion about what these technologies should become and being an active, not passive participant." 34 This approach is similar to the critical thinking and evaluative aspects of information literacy, although cyberliteracy is specific to the Internet and Web environments. Gurak argues that, to be cyberliterate, an individual must be "more than a user" of technology and must "become an active participant in the discussion." 35 Similarly, Evelyn Stiller and Cathie LeBlanc reinforce the participatory aspects of cyberliteracy and argue that, to promote this form of literacy, educators must teach students "how to critically consume Internet content as well as how to use a variety of media on the Internet to express their own viewpoints." ${ }^{\prime 36}$ They define specific elements of cyberliteracy that include such abilities as "using the Internet to express political, creative, and artistic viewpoints" ${ }^{\prime \prime 3}$ and understanding "the variety of social and ethical issues associated with Internet communication." ${ }^{38}$ Other related elements include an awareness of online communications, privacy issues, diversity online, and accessibility. ${ }^{39}$ Cyberliteracy shares the overall goals of information literacy to move beyond basic computer literacy and to encourage critical thinking as an active and informed citizen. At the same time, cyberliteracy is more specifically related to issues surrounding Internet use and participation than information literacy definitions tend to articulate.

\section{Information Fluency}

In 1999, the Committee on Information Technology Literacy published Being Fluent with Information Technology. ${ }^{40}$ Fluency shares one of the primary goals of information literacy: for learners to acquire a deeper level of comprehension and engagement with ideas than just learning how to use a computer. It is described as "a set of intellectual capabilities, conceptual knowledge, and contemporary skills associated with information technology," while information literacy is a critical thinking activity focused on research and author practices. ${ }^{41}$ Information Fluency developed at a time when advances in desktop computing, and the emergence of networks, through linked computers, the Internet, and Web, changed how we understood technology from an area specialization for experts, to a common set of tools that influenced many aspects of life. This shift in emphasis required a more comprehensive approach to technology than computer literacy offered. In today's social media environment especially, information and technology continuously intersect through a range of Web-based applications that allow individuals to easily access, produce, and share information.

Fluency and information literacy are similar in many ways and share a common objective for moving beyond the acquisition of basic computer skills. The differences between information fluency and information literacy, however, were clearly defined by the original document, Being Fluent with Information 
Technology, which states: "information literacy and FITness are interrelated but quite distinct." 42 While information literacy is discussed as a critical thinking activity focused on research and author practices, fluency is described as "a set of intellectual capabilities, conceptual knowledge, and contemporary skills associated with information technology." 43 ACRL made a clear distinction between the two terms as well by asserting that: "information literacy initiates, sustains, and extends lifelong learning through abilities which may use technologies but are ultimately independent of them." ${ }^{44}$ This is an intentional separation from any specific technology, in support of a wider perspective on information competencies. At the same time, however, it diminishes the relationship between the two concepts and the ways in which information literacy informs fluency and related digital competencies.

The standard definitions of information literacy share many commonalities with related literacy types, with a particular emphasis on discrete information skills. Most of the differences are based on changes in technology, such as digital and networked environments.

\section{Toward a Metaliteracy}

Within the field of library and information science, traditional definitions of information literacy have been challenged, suggesting a need for an expanded metaliteracy framework. James Elmborg argues for a "critical information literacy" model based on the influence of critical pedagogy and critical literacy theory. He argues that "by developing critical consciousness, students learn to take control of their lives and their own learning to become active agents, asking and answering questions that matter to them and to the world around them." ${ }^{45}$ Similarly, Troy A. Swanson argues that, in making a transition from a print-based culture to a Web environment, we must provide students with a critical perspective to learn more about information itself and how to use it in an empowering and participatory manner. ${ }^{46}$ James W. Marcum asserts that the broadly defined goals of information literacy are not realistic and that in practice it is too limited, especially because of what he sees as an overemphasis on skills development. ${ }^{47}$ He suggests that information literacy attempts to cover too much while being exceedingly focused on print culture, which diminishes the importance of new media environments. ${ }^{48}$ Marcum carefully examines related literacy terms, but he does not situate information literacy as an overarching competency for the other models. Instead, he calls for a refocused approach that incorporates technology considerations.

Christine Pawley agrees with Marcum's assertion that information literacy has been the primary professional focus of the field of library and information science for some time, responding to the challenges of technology and the Internet in particular. But she identifies an inherent divide in the term itself, which she sees as "contradictory" because it creates "a tension between conflicting ideals of, on the one hand, a promethean vision of citizen empowerment and democracy, and, on the other, a desire to control 'quality' of information." 49 Pawley also challenges the conception of "information as a thing" because of the limited expectation that libraries organize and facilitate information as a commodity. She argues that we need to move beyond a skillsbased approach to information literacy, especially in response to technological innovations such as the Web. Pawley asserts that "rather than focusing only on negotiating some essentialist concept of the term and on the best techniques for transmitting the agreed-upon skills, we should also be debating what, fundamentally, we are trying to do when we engage in information literacy practices, however defined"50 As a starting point, Pawley challenges the field to engage in a "critical approach to information literacy" that moves beyond skills development, addresses the inherent contradictions of 
the term itself, thinks beyond information as a commodity, and instead focuses on the production of knowledge in collaboration with others.

In his analysis of "new literacies," John Buschman argues that the literature focuses too much on trends in new technology, especially as an influence on literacy, and that we do not need to separate information literacy from its origins in bibliographic instruction. ${ }^{51}$ Similar to Pawley, Buschman suggests that we need a more coherent and complex response to new media than simply focusing on skills development and the technologies themselves. Buschman, however, supports a broader historical view of literacy and states that "we have to question the inherent claim or assumption that IL must of necessity distinguish itself from its history of bibliographic instruction (and its variants) by invidious distinctions with 'old-fashioned' forms of literacy." 52 This perspective challenges the ideas prevalent in new media studies that emerging technologies are in any way revolutionary and require a new form of literacy. He asserts that "while a certain amount of sobriety concerning the electronic and digital age seems to have finally taken hold, we are currently faced with high-flying claims about fundamental cognitive shifts being rapidly brought about by that age." 53 For Buschman, the newness of an approach should not take precedence over well-established practices that have been developed within the field of information literacy and bibliographic instruction. He argues that our approaches to literacy "will be stronger acknowledging their cognitive and epistemological foundations" that support an intellectual core based on critical reading and thinking. ${ }^{54}$ This is a useful perspective as we argue for information literacy as a metaliteracy, because this approach requires us to recognize the relationships between core information literacy competencies and emergent literacy frameworks. At the same time, however, metaliteracy is a concept that promotes active engagement with emerging technologies and learnercentered production of information. Rather than separate information literacy from other forms of literacy, we argue that a comprehensive understanding of information and related competencies are central to these literacy concepts. This approach is grounded in the idea that emerging technologies are inherently different from print and require active engagement with multiple information formats through different media modalities.

While ongoing changes in technology have created a range of responses in the field, calling for a fundamental shift in how we understand information literacy itself, other perspectives support the active use of emerging technologies in information literacy contexts. For instance, Kara Jones explores the potential for using social technology to support information literacy and argues that "online social technologies such as Weblogs, wikis and social bookmarking can be used to build fluency in the skills required to be information literate." ${ }^{55}$ She matches several social technologies with information literacy competencies based on an "information cycle" model that "helps demonstrate to learners that social technologies can be used to identify and locate information at the stage when it's most difficult to find, as research in progress." ${ }^{56}$ Jones argues that these resources are useful as sources of information and as tools for exploration in support of "higher-order thinking skills," but she does not suggest revisions to the existing information literacy characteristics based on this approach. ${ }^{57} \mathrm{Craig}$ Gibson asserts that academic librarians are faced with many "nomenclature challenges" associated with the "sometimes overlapping and sometimes diverging cluster of terms centered on technology skills-information technology (IT) fluency, technology literacy, computer literacy, digital literacy, and others. ${ }^{\prime 58} \mathrm{He}$ argues for an integrated and collaborative approach to information literacy instruction that infuses technology into the skill set. ${ }^{59}$ Gibson is interested in a blended 
learning model that incorporates both information fluency and information literacy into the curriculum and in support of lifelong learning goals, but he does not propose changes to information literacy within this combined context. ${ }^{60}$

Kimmo Tuominen examines the impact of emerging technologies on information literacy and states that "new kinds of literacies are needed in dealing with the various born-digital document types and genres-like sms messages, emails, blogs, wikis, podcasts and RSS feeds-that are forming an increasingly larger part of our present day and future information environments." 61 Tuominen suggests that Web 2.0 technologies have led to an "erosion of information contexts," based on anonymous, fluid, and virtual spaces. ${ }^{62}$ The author calls for a redefinition of information literacy as a 2.0 framework that prioritizes "users' conceptual understandings of their information environment" over traditional skills, such as the ability to conduct Boolean searches. ${ }^{63}$ Beyond the field of library and information science, the term "transliteracy" has emerged in response to developments in new media. According to Thomas et al., transliteracy is defined as "the ability to read, write and interact across a range of platforms, tools and media from signing and orality through handwriting, print, $\mathrm{TV}$, radio and film, to digital social networks. ${ }^{\prime 64}$ As with metaliteracy, the term transliteracy is intended to unify competing approaches to literacy. According to the authors, "transliteracy is an inclusive concept which bridges and connects past, present and, hopefully, future modalities," which indicates a broader need to converge multiple methodologies, including analog and digital formats.

In her discussion of new media literacy, Renee Hobbs identifies the "key unifying principles" of media literacy, based on the idea that messages are socially constructed "representations of the world." ${ }^{\prime 6}$ Her definition recognizes the importance of the economic and political considerations of message construction, as well as awareness of audience and the ways that messages are interpreted in different ways. Hobbs supports an approach to media literacy that places the learner at the center of "mediamaking," but not simply to promote the experience of production. ${ }^{66}$ Hobbs argues that "there is so much to learn about yourself and the media system that surrounds you-and some of this learning occurs best through practical experience, working in a team, creating a real media message for a real audience." ${ }^{67}$ Based on a research study on media literacy acquisition, Hobbs argues that "students who received medialiteracy instruction were more likely to recognize the complex blurring of information, entertainment, and economics that are present in contemporary nonfiction media." ${ }^{\prime 8}$ This finding reinforces the idea that media literacy instruction, with an emphasis on user-centered production of information, advances student learning beyond discrete skills in support of higher order critical thinking. The same study found that "students who received media-literacy instruction appeared to have a more nuanced understanding of interpreting textual evidence in different media formats to identify an author's multiple purposes and intended target audiences." 69 Traditional definitions of information literacy do not consider collaborative media production and the impact on learning, which is why we need an expanded metaliteracy model with an emphasis on active production and sharing of new knowledge through technology.

As we have seen, there are many challenges to the standard information literacy definition based on the emergence of new social technologies. While new literacy movements have similar foundation elements to information literacy, specifically related to critical reading and critical thinking, as well as proficiencies in finding, synthesizing, and creating information, differences are often emphasized based on the specificity of technology or media formats. As each new form of literacy is in- 
troduced, the shared literacy goals related to critical thinking and information skills are often overlooked, creating an unnecessary divide between information literacy and other literacy types. The information literacy literature has also contributed to this separation in an effort to clarify important distinctions between information and computer skills, or between traditional bibliographic instruction and new media literacy. Metaliteracy reinforces stronger connections between information literacy and other literacy frameworks. This approach looks at the foundation principles that unite information and technology, rather than focusing on differences based on discrete skills, distinct technologies, or media formats.

\section{Metaliteracy}

Metaliteracy is an overarching, self-referential, and comprehensive framework that informs other literacy types. Information literacy is the metaliteracy for a digital age because it provides the higher order thinking required to engage with multiple document types through various media formats in collaborative environments. Many of the information literacy characteristics are central to multiple literacy perspectives, defining a literacy framework about literacy. Metaliteracy provides an integrated and all-inclusive core for engaging with individuals and ideas in digital information environments.

Based on the prevalent information literacy definitions, someone who is information literate knows how to determine when information is needed, access information using a range of tools, evaluate the information through critical thinking and analysis, and incorporate information into something new through a synthesis of materials. These competencies require individuals to understand and use information based on critical reading and writing. While media and technology formats continue to change, the comprehensive nature of information literacy prepares individuals to adapt to shifting information environments. In many ways, this is a process of learning how to learn. Information-literate individuals acquire the ability to understand information using different forms of technology. They apply information knowledge gained from a wide range of verbal, print, media, and online sources and continuously refine skills over time. This constitutes a practice of critical engagement with one's world as active and participatory learners.

In proposing metaliteracy as overarching and related to many literacy frameworks, we suggest changes to the way information literacy is perceived as a primarily skills-based approach to learning. This is a shift in emphasis from discrete skills to collaborative production and sharing of information using participatory interactive technologies. Metaliteracy provides the integral foundation for additional literacy types, recognizing social media environments as active collaborative spaces for accessing and sharing one's findings. This requires us to move beyond skills development to an understanding of information as dynamically produced and shared online. As part of this process, we examine metaliteracy in practice, describing the challenges of emerging technologies and offering recommendations for actively engaging students with new media.

\section{Metaliteracy in Practice Understand Format Type and Delivery Mode}

In today's new media environment, information seekers must not only determine the extent of information needed, but also the format and delivery mode of the information itself. While this situation is not new, format choice applies to a far wider range of topics now than it did when ACRL originally defined the information literacy outcomes. In the past, those researching art, for example, would inherently understand the need to find visual images as well as written documents to support the historical context or external interpretations of the image itself. Due to the expanding range of audio, video, 
and image types currently available, all researchers must decide if nonprint formats will enhance their search, and then be familiar with the tools needed to find them, such as Flickr, YouTube, or other Web-based tools for uploading, tagging, and sharing digital information. In these instances, the researcher must understand the format type and how it functions as an interactive social media tool to make informed determinations about the content. These resources also combine text, image, video, and meta-information through the medium itself, creating multipurpose information types that require a critical analysis of the integrated format.

As the number of information sources continues to increase, skills connected with determining the extent of information required for a particular search must be more finely honed. A sense of information overload or perhaps uncertainty about how to make choices among many options may cause researchers (especially novice searchers) to truncate or give up on the process of assessing how much information is needed, or to abrogate prior determination, basing decisions solely on results retrieved while searching. It is critical that decisions about how much and what type of information is needed should be revised throughout the search process, yet an initial goal should be set. Searchers may also access user feedback elements in information tools, such as Amazon's book or media reviews, to revise their search parameters. They must be careful about doing so, taking time to assess the applicability of such feedback to their actual needs. In addition, the passive recommendations from users at social bookmarking sites such as Delicious must be understood within the context of a user-centered information environment. This type of unfiltered and unedited feedback transforms the determination of the amount of information needed into a far more social activity than it has been in the past. The social media environment has the effect of collapsing categories within the existing information literacy model: deciding on what information is needed may occur at the same time as information is accessed, so the evaluation of information needs to take place earlier in the process.

\section{Evaluate User Feedback as Active \\ Researcher}

Web-based applications have completely changed our expectations of where and how to find information. Long before the emergence of Web 2.0 and mobile technologies, the omnipresence of the Web, and the ease and convenience of using it, made it the central and perhaps exclusive location for those seeking information. As Web resources develop and expand, it is the increasingly rare researcher who starts a quest for information using books or other long-established formats such as paperbound scholarly journals. They may use books or journals eventually, but will have done so through the prism of Google Books, Google Scholar, Amazon, or perhaps through an e-book reader such as Kindle. This situation points to a critical issue related to finding information effectively and efficiently: are the most effective tools for the type of information needed being used and how do we efficiently incorporate the new social resources into our search process? Is Google or another basic search engine being applied to find information that might better be sought through more sophisticated and targeted resources such as specialized search engines or databases that index the literature of a field? Google Scholar and Google Books continue to expand and improve and the user-friendly search box design has been incorporated into Web-based library interfaces as well. The ease of use and ubiquity of resources such as the generic Google search feature, along with the certainty of results, however, lulls information seekers into a false sense of security that they have found what there is to be found.

Web 2.0 both exacerbates and mitigates this widespread searching behavior tendency. The ability to find others' opinions 
about information sources, such as the book ratings and comments on bookseller and social networking sites, might deter searchers from finding more authoritative sources of information, as it also expands the possibilities for locating resources. User comments and star ratings are helpful markers leading the way to different sources of information previously unavailable in a scholarly search, but this information must be contextualized within a larger process that critically evaluates the validity and reliability of all source types, including those that are user-generated. Similarly, tweets and Facebook comments are convenient sources of information for sharing links to Web sites, citations, and freely available scholarly resources, but this information requires the researcher to filter through vast amounts of usergenerated content that is not always reliable or relevant to a particular search. The push technology available with many online resources adds to the convenience: information will come to the searcher, but the searcher must develop a critical thinking filter to continuously differentiate the usable from the unusable. If the filter is not already present in the medium itself, the information user must develop one as part of the search process.

Social media provides multiple pointers to excellent sources of information, even though some of the information may not be exactly what is needed. Blogs and wikis hosted by experts in a field provide resources to learn about reliable sources of information through the Web. For example, librarians with subject expertise have created LibGuides and other resources on a range of topics that constitute the ideal places to start. In addition, Web sites that provide scholarly preprints and the comments of other scholars in the field provide useful sources of information as well. The key to this activity in a new media environment is for the information-literate individual to be able to find information using a range of media formats. This may be especially challenging when the types of tools and means of access to information are nonhierarchical and always changing. For example, waiting for tweets to arrive, scanning blogs, or reviewing Facebook postings may be more passive than active if the researcher does not take a criticalthinking approach to accessing information. This requires an understanding of the information type as well as the interactive formats for acquiring information. Research in these environments must be focused and assertive, allowing the user to actively participate in a dialogue with experts and nonexperts, and differentiating between wide-ranging tools as well as formal and informal sources. Social media researchers must be aware of the types of tools available and how each functions as an interactive and participatory resource.

\section{Create a Context for User-generated Information}

It has become dramatically more difficult for information seekers to determine who is producing the information they are considering and to establish the author's expertise than it was prior to the emergence of social technologies. This requires an increased emphasis on the evaluation of information sources and a reframing of how to do so in these new contexts. Wikipedia, for example, challenges our understanding of who produced the information while reinforcing the importance of peer review (the community of writers and editors provide this function in a decentered manner). The markers that provided clues for researchers in the past-such as reputation of a journal or of a book publisher-do not exist for many information sources currently available. The process of reviewing materials in Wikipedia, for example, requires the reader to look for other clues, such as the history of postings, dates, references, and cross-checking of resources. If traditional meta-information about a document does exist, it may be disassociated with the content of the material. For instance, information seekers frequently do not see a complete entity (that is, a book or a journal) in a new media 
environment, but only discover physically discrete elements through their searches, such as snippets of texts in Google Books (depending on the level of copyright protection), tags created by users, links to Web resources, wiki author history and dates, bookmarks to resources, and individual articles pulled up from a database or Google Scholar search. In addition, a lack of context occurs through RSS feeds on Web sites or results returned through a federated search engine. Because of the nature of disconnected pieces of information and shifting contexts, researchers may not even recognize the importance of looking for those identifying features that more experienced searchers rely upon. Information seekers may use factors such as ease of obtaining the full text of an item or the actual image, succinctness of the material, visual presentation and usability, and other elements that we now consider to locate information. This requires an understanding of the materials presented, as well as the associated meta-information and source type.

As researchers encounter the recommendations of others, such as comments or ratings on bookseller Web sites, tweets, blog replies, tags, bookmarks, or Facebook postings, they must contextualize this information within a decentered environment that connects the professional and novice and makes accessible both formal and informal sources of information. In this setting, the evaluation of information is ongoing and must consider the difference between referrals to a wide range of sources and the information itself. In addition, the popular opinion about a source does not necessarily equal quality, and the expertise of those commenting must be considered. At the same time, a large concentration of positive recommendations to information sources (such as user-generated book or media reviews or tweets from theorists or professionals in a particular field) are useful indicators to move in a certain direction in pursuit of reliable information sources. Although the information seeker may find it difficult to determine if there is expertise involved in many social media environments, especially if there is anonymity, this reinforces the need to continuously evaluate and ask questions as part of the research process.

\section{Evaluate Dynamic Content Critically}

Information seekers in the Web 2.0 environment have easy access to a far broader range of materials than researchers in the past did. They must have the ability to synthesize these disparate information formats, which is more challenging than when most academic sources were written as texts only, clearly defined as scholarly, and focused on the same topic. This requires that researchers understand the visual cues for scholarly materials within a digital context (author names or online pseudonyms, date of posting, association logos, organizational strategy, links to resources, and so on), or their ability to amalgamate what they have learned will be diminished. For example, in the social networking environment of Twitter, information seekers must actively pursue experts, professionals, and organizations or associations that continuously tweet about scholarly issues and report on the changing dynamics of a conference, field of study, or the medium itself. While this kind of fluid and concise information may not necessarily be scholarly, it may lead in the direction of relevant materials that an individual could incorporate into his or her search process or frame of reference. As an active participant in this process, today's information seekers are also able to use Twitter to post questions about information searches, share their own findings, and follow others interested in the same topics.

Because an individual or group is able to create an online forum for expressing opinions that in most cases would have been local in the past, today's information-literate individual must be able to recognize and appropriately synthesize conflicting views. Information sources based on opinion are more prevalent in participatory online communities, such 
as blogs, Second Life, Twitter, and other Web 2.0 sites. For instance, Facebook and LinkedIn provide resources for creating online bulletin boards, as well as fan and group pages for professional organizations and associations to interact with members and interested participants. This requires an understanding of how these sites work and how to effectively connect with others using these tools. It also leads to questions about the weight that should be assigned to each piece of information presented or discussed in these digital spaces. This is not a new approach to information literacy and remains closely tied to the evaluation of information, but it does assume increased significance today.

With the prevalence of online forums designed for expressing one's viewpoints in dialogue with others, the information seeker must locate the dividing line between facts and opinions before incorporating these ideas into his or her own knowledge. It may not always be easy to identify the difference online, but an information-literate researcher must review this dynamic content critically as part of the evaluation process. It is also important to evaluate the forum itself as either a formal or informal group and to identify whether or not an online discussion is part of a professional association or less clearly defined group of participants interested in a topic. Other formats now commonly found online, such as audio and video clips, or materials accessed through the virtual world of Second Life, also need to be appraised, but the tool kit is not entirely the same as for reviewing print sources. As such, the assessment of these materials must consider the reliability of the media site, the authenticity of the materials posted, and the relevance of the user-centered tags and comments. Currently, there are few if any scholarly review outlets for these kinds of emerging media resources. This places further emphasis on the information seeker to be a critical agent in this process, actively engaging in these social environments, asking vital questions of other partici- pants, critically evaluating the materials presented, and carefully incorporating the information into their own learning.

\section{Produce Original Content in Multiple Media Formats}

The ACRL Information Literacy Competency Standards identified the importance of using information for specific purposes and recognized diverse media beyond print including digital texts. ${ }^{70}$ But this competency does not fully address the broader knowledge required for producing dynamic online content as an individual and in collaboration with others. Producing original content is especially relevant today with social media formats that allow for multiple uses of information that are as diverse as the means for accessing and evaluating it. As producers of digital documents, information-literate individuals must make critical choices about the precise media format to articulate ideas and the online site or tool for doing so. This may include social networking sites such as Facebook, community-based wikis, blogs such as Blogger or WordPress, microblogs such as Twitter, the virtual world of Second Life, or communications through mobile applications. The definition of what constitutes a document in these contexts varies considerably, from collaborative writing in a wiki, to a textbased posting on a blog (with potential for participant comments), to a brief 140-character tweet on Twitter. It may also include the development of an island on Second Life (or an uploaded document in any form to this virtual space), or a digital text or image transferred through a mobile device. These examples demonstrate a significant expansion of the uses of information that extend beyond print and digital texts that replicate print in some way through similar organization and formatting. Emergent technologies present information in new ways through the fragmentation of ideas, links to resources, a shifting or transient sense of time and place, and the blurring of lines between actual and virtual space, as well 
as between text and image. Informationliterate individuals must be aware of these fundamental changes in various document types and media for the development of their own ideas in these settings.

\section{Understand Personal Privacy, Information Ethics and Intellectual Property Issues}

Information literacy was initially conceived as a lifelong learning process that prepared individuals to be active and engaged citizens. This is especially relevant in social media environments that embody a democratic process for making contributions in collaboration with others. As individuals express their views publicly via social networking and online communities, we must reflect on issues of personal privacy, information ethics, and intellectual property. In addition, information access issues continue to play an increasingly prominent role in today's digital society and how or even if we communicate online. Information access is often mediated by social and economic considerations that determine the extent to which individuals participate. For instance, published articles in traditional journals and scholarly books are primarily accessible via academic libraries that purchase these materials. Initiatives in open learning continue to rapidly expand the scope of freely available resources, but this work may not be readily available to the information seeker in an initial search and may require a more complex process with revised search terms. The proper attribution of sources is also a relevant concern in these environments but is especially challenging when authorship is unknown or difficult to determine in open, collaborative environments. An information-literate individual must be aware of these information surroundings and understand the ever-increasing impact that information and emerging technologies have on our lives. This requires an ongoing exploration of the legal, economic, political, and social issues that mediate our access to technology and often define the types of documents we evaluate and use.

\section{Share Information in Participatory Environments}

The ways in which information might be accessed and shared has increased exponentially with emerging social technology. In the past, written documents were perhaps the most frequent tangible forms for sharing information and were mostly found in the world of academe and in work settings. In many cases, these written items only reached a very select group of readers. The early Web featured static pages and sites that reflected similar formatting of standard text pages and provided hypertext links to other resources. This did not allow for the kind of dynamic interaction available in today's networked Web environment, where people create documents in multiple forms and reach a wide audience instantly. Web 2.0 has made it easy to communicate information and ideas with people worldwide in many forms, including video, blogs, tweets, wiki contributions, social networking posts or comments, and interactions in the virtual world of Second Life. While some formats may rely solely upon the creator's research about and knowledge of a topic, and the articulation of ideas through text, others may require the ability to create graphics, video, audio, or (in the case of Second Life) avatars that represent an individual's virtual identity. Professional expertise in graphic design, high-quality video or audio, computer programming, or even HyperText Markup Language (HTML) are not as relevant in today's Web 2.0 environment as they were in previous iterations of the Web. Many social media applications are user-friendly, which has contributed to the rapid expanse of these tools. At the same time, however, auxiliary skills that contribute to the successful information in these environments are still essential, such as the ability to organize, format, and revise the information to be conveyed.

This reframing of information literacy as a metaliteracy challenges the traditional definitions of the term in response to the innovations of social media and 
online communities. The purpose of this approach is to understand information production and sharing as central to participating in these collaborative environments. Metaliteracy moves beyond an exclusively skills-based approach to information and emphasizes collaboration in the development and distribution of original content in synchronous and asynchronous online environments.

\section{Conclusion}

Metaliteracy provides the foundation for media literacy, digital literacy, ICT literacy, and visual literacy. While information literacy prepares individuals to access, evaluate, and analyze information, metaliteracy prepares individuals to actively produce and share content through social media and online communities. This requires an understanding of new media tools and original digital information, which is necessary for media literacy, digital literacy, and ICT literacy. The ability to evaluate and use visual information is also supported by this approach, not only for the appreciation of visual images, but for the development of new visuals as well. Information literacy supports many of the goals of cyberliteracy and information fluency. For example, the ability to critically evaluate and synthesize Internet content prepares individuals to be active participants online, which is central to cyberliteracy. In addition, the overall critical-thinking abilities of information literacy create a necessary foundation for information fluency, which allows individuals to continuously adapt to new tech- nologies. These are just a few examples of the most clearly defined connections between information literacy and several current literacy approaches. As a metaliteracy, information literacy provides many foundation elements for literacy categories beyond those identified here.

In summary, metaliteracy provides a conceptual framework for information literacy that diminishes theoretical differences, builds practical connections, and reinforces central lifelong learning goals among different literacy types. Rather than envision these methods as unrelated or disconnected, we see information literacy as the essential framework that informs and unifies additional literacy types. Through this approach, we recognize the standard information literacy characteristics (determine, access, evaluate, incorporate, use, understand) as integral to related literacy formats. We also argue that producing and sharing information are significant activities for lifelong learning in social media environments and online communities. While the type of information may change from one format to another (from print, to Web page, to multimedia file, to learning object, to collaborative document), the abilities to determine, access, evaluate, incorporate, use, understand, produce, collaborate, and share information are common considerations. Information itself is constantly variable, and to fully gain knowledge about interacting with it as something dynamic and collaboratively produced requires the ability to adapt to shifting formats.

\section{Notes}

1. Craig Gibson, "Information Literacy and IT Fluency: Convergences and Divergences," Reference \& User Services Quarterly 46, no. 3 (2007): 24.

2. American Library Association, Presidential Committee on Information Literacy: Final Report, II28 (1989). Available online at www.ala.org/ala/mgrps/divs/acrl/publications/whitepapers/ presidential.cfm. [Accessed 6 July 2009].

3. Society of College, National and University Libraries, Briefing Paper: Information Skills in Higher Education (1999). Available online at www.sconul.ac.uk/groups/information_literacy/ papers/Seven_pillars2.pdf. [Accessed 6 July 2009].

4. Ibid., 6 .

5. Ibid., 6 . 
6. Information literacy competency standards for higher education. 2000 Chicago: Association of College \& Research Libraries.

7. Society of College, National and University Libraries, Briefing Paper, 8.

8. Middle States Commission on Higher Education, Developing Research and Communication Skills: Guidelines for Information Literacy in the Curriculum (Philadelphia: MSCHE, 2003), 11-12.

9. Society of College, National and University Libraries, Briefing Paper, 6.

10. Ibid., 5 .

11. Sheila Webber, Society of College, National and University Libraries, The Seven Headline Skills Expanded (2008). Available online at www.sconul.ac.uk/groups/information_literacy/headline_skills.html. [Accessed 6 July 2009].

12. Ibid.

13. Information literacy competency standards for higher education. 2000 Chicago: Association of College \& Research Libraries.

14. Aspen Institute, Aspen Institute Report of the National Leadership Conference on Media Literacy (1992). Available online at www.medialit.org/reading_room/article582.html. [Accessed 5 August 2009].

15. Center for Media Literacy, Literacy for the 21st Century: An Overview and Orientation Guide to Media Literacy Education (2008). Available online at http://www.medialit.org/reading-room/literacy21st-century-overview-orientation-guide-media-literacy-education. [Accessed 22 November 2010].

16. Ibid., 22.

17. Ibid., 22.

18. Ibid., 22.

19. American Library Association, Presidential Committee on Information Literacy: Final Report (1989).

20. Paul Gilster, Digital Literacy (New York: John Wiley \& Sons, 1997): 1.

21. Ibid., 2.

22. Barbara R. Jones-Kavalier and Suzanne L. Flannigan, “Connecting the Digital Dots: Literacy of the 21st Century," Educause Quarterly 29 (Nov. 2006): 9. Available online at http://net.educause. edu/ir/library/pdf/eqm0621.pdf. [Accessed 6 August 2009].

23. Ibid., 9 .

24. International ICT Literacy Panel, Digital Transformation: A Framework for ICT Literacy (2007). Available online at http://www.ets.org/Media/Tests/Information_and_Communication_Technology_Literacy/ictreport.pdf. [Accessed 22 November 2010].

25. Ibid., 18.

26. Ibid., 20.

27. Original definition of visual literacy is available online at the International Visual Literacy Association: www.ivla.org/org_what_vis_lit.htm. [Accessed 6 August 2009].

28. Jones-Kavalier and Flannigan, "Connecting the Digital Dots," 9.

29. Ibid., 9 .

30. Ibid., 9 .

31. Peter Felton, "Visual Literacy," Change (Nov./Dec. 2008): 60.

32. Ibid., 61.

33. Laura J. Gurak, Cyberliteracy: Navigating the Internet with Awareness (New Haven: Yale University Press, 2001).

34. Ibid., 27.

35. Ibid., 28.

36. Evelyn Stiller and Cathie LeBlanc, "From Computer Literacy to Cyber-Literacy," Journal of Computing Sciences in Colleges 21, no. 6 (June 2006): 4-13.

37. Ibid., 6 .

38. Ibid., 6 .

39. Ibid., 6 .

40. Committee on Information Technology Literacy, Being Fluent with Information Technology (1999). Available online at www.nap.edu/openbook.php?record_id=6482. [Accessed 7 August 2009].

41. Ibid., 49.

42. Ibid.

43. Ibid.

44. Information literacy competency standards for higher education. 2000 Chicago: Association of College \& Research Libraries.

45. James Elmborg, "Critical Information Literacy: Implications for Instructional Practice," Journal of Academic Librarianship 32 (Feb. 2006): 192-99.

46. Troy A. Swanson, "A Radical Step: Implementing a Critical Information Literacy Model," portal: Libraries and the Academy 4, no. 2 (Apr. 2004): 259-73.

47. James W. Marcum, "Rethinking Information Literacy," Library Quarterly 72 (Jan. 2002): 1-26.

48. Ibid., 20.

49. Christine Pawley, "Information Literacy: A Contradictory Coupling," Library Quarterly 73 
(2003): 422-52.

50. Ibid., 445.

51. John Buschman, “Information Literacy, 'New' Literacies, and Literacy," Library Quarterly 79 (Jan. 2009): 95-118.

52. Ibid., 110.

53. Ibid., 111.

54. Ibid., 112.

55. Kara Jones, "Connecting Social Technologies with Information Literacy," Journal of Web Librarianship 1, no.4 (2007): 67-80.

56. Ibid., 76 .

57. Ibid., 77.

58. Gibson, "Information Literacy," 23-59.

59. Ibid., 59.

60. Ibid., 59.

61. Kimmo Tuominen, "Information Literacy 2.0," Signum 5 (2007): 6-12.

62. Ibid., 7.

63. Ibid., 12.

64. Sue Thomas et al, “Transliteracy: Crossing Divides," First Monday 12 (Dec. 2007). Available online at www.uic.edu/htbin/cgiwrap/bin/ojs/index.php/fm/article/view/2060/1908. [Accessed 30 December 2009].

65. Renee Hobbs, "Media Literacy, General Semantics, and K-12 Education," ETC: A Review of General Semantics 61 (2004): 24-28.

66. Ibid., 27.

67. Ibid., 27.

68. Renee Hobbs, "Measuring the Acquisition of Media Literacy Skills," Reading Research Quarterly 38, no. 3 (July/Aug./Sept. 2003): 351.

69. Ibid., 351.

70. Information literacy competency standards for higher education. 2000 Chicago: Association of College \& Research Libraries.

\section{american PUblic health association}

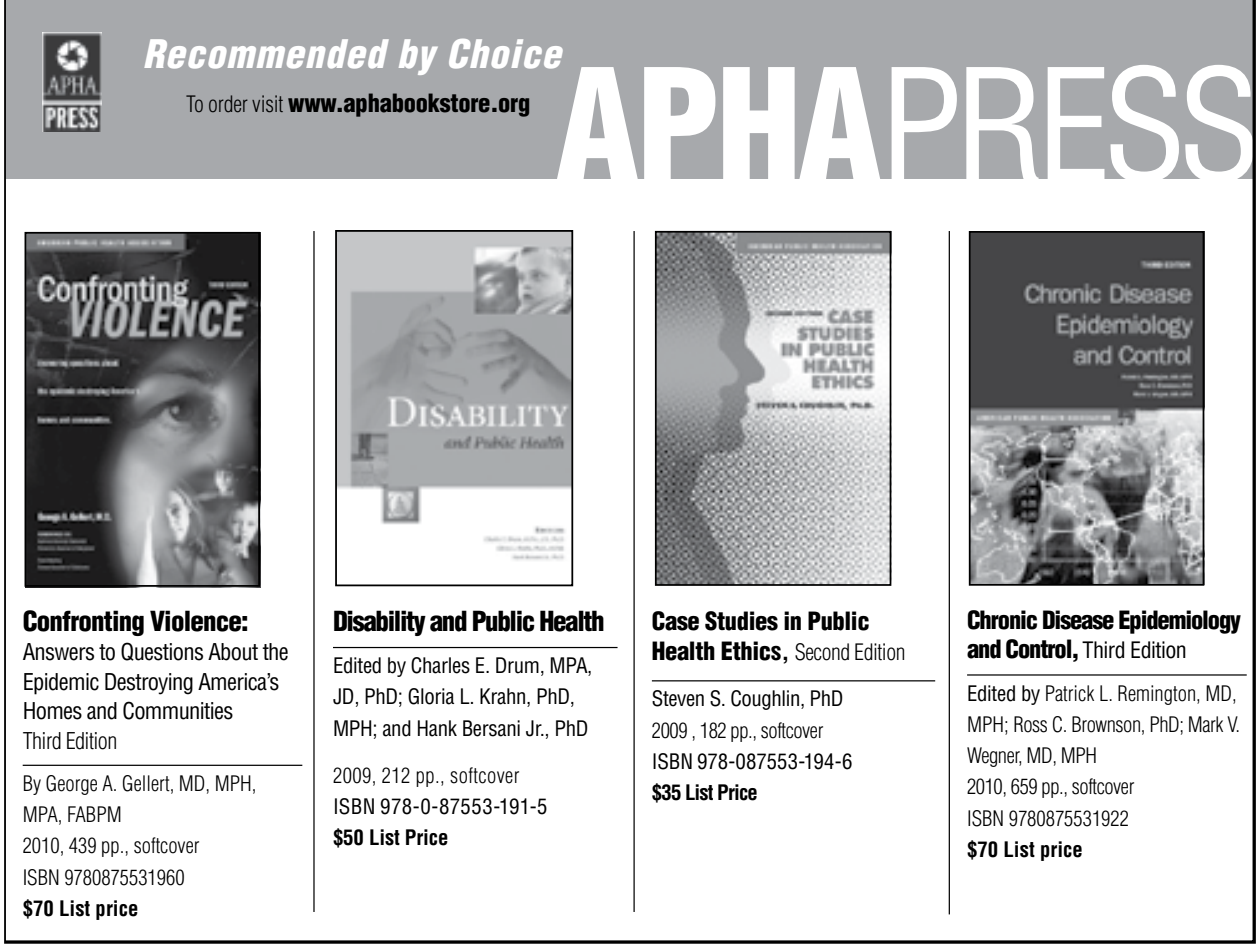

